\title{
Event-adjusted evaluation of weather and climate extremes
}

\author{
M. Müller ${ }^{1,2}$ and M. Kaspar ${ }^{1}$ \\ ${ }^{1}$ Institute of Atmospheric Physics, Academy of Sciences, Prague, Czech Republic \\ ${ }^{2}$ Charles University, Faculty of Science, Prague, Czech Republic \\ Correspondence to: M. Müller (muller@ufa.cas.cz)
}

Received: 7 August 2013 - Published in Nat. Hazards Earth Syst. Sci. Discuss.: 6 September 2013

Revised: 20 January 2014 - Accepted: 29 January 2014 - Published: 28 February 2014

\begin{abstract}
After an overview of existing methods, we present a novel method of "event-adjusted" evaluation of extremeness of weather and climate events. It is based on optimization of both the considered area and the time duration for every event. The method consists of three steps: (i) estimation of return periods of a representative variable at individual sites, performed separately for various time windows; (ii) spatial interpolation of the point return period data; and (iii) searching the area and the time window in which the extremeness of the event was maximum. The extremeness is quantified as the common logarithm of the spatial geometric mean of the return periods multiplied by the radius of a circle of the same area as the one over which the geometric mean is taken. The maximum product is referred to as the weather extremity index (WEI). Two precipitation events, which affected the Czech Republic in May and in August 2010, were evaluated by the WEI for illustration. Validation of the method on sufficiently long data series is still needed. Moreover, the WEI is generally applicable regardless of the studied phenomenon (heavy rains, heat waves, windstorms, etc.). This makes it possible to study various weather and climate extremes from the viewpoint of possible recent and future changes in their frequency, seasonal distribution, and circulation conditions accompanying them.
\end{abstract}

\section{Introduction}

Weather and climate extremes have long been the focus of atmospheric sciences because of their significant social and economic impacts (Cutter et al., 2008). This effort has even increased during recent decades in the context of discussions of climate change impacts (Beniston and Stephenson, 2004). In the 1980s, Wigley (1988; reprinted in 2009) showed that even a small shift in the mean and variance of a climate variable might lead to a strong shift in the frequency of respective weather and climate extremes. Since this time, many studies have focused on the analysis of past and possible future trends in extremes (e.g., Alexander et al., 2006; Klein Tank et al., 2006). Katz (2010) noted that not only the frequency but also the magnitude of extreme events should be considered in this type of study. The reason is that detected trends in more extreme events can be more (or less) significant than trends in moderate extreme events (Hegerl et al., 2004).

A similarly large group of papers is concerned with meteorological causes of weather and climate extremes (e.g., Homar et al., 2007; Lupikasza, 2010). As in the abovementioned type of study, the authors often select a group of extreme events and avoid quantifying their extremeness. However, considering all events as "equally extreme" can thwart discovering substantial differences in causes between more and less extreme events (Müller and Kaspar, 2010).

Obviously, one of the crucial challenges to authors of both presented types of studies is the correct selection of extreme events and evaluation of their extremeness. Our research is motivated by the fact that the selection method can substantially influence the results of a study (Visser and Petersen, 2012). In accordance with Diaz and Murnane (2008), we differentiate between short-term weather events (e.g., heavy rainfall) and longer-lived climate events (e.g., extra wet season). We focus mainly on weather extremes in the present study. The extremeness of climate events can be evaluated by similar methods when only the type of input data makes the difference (e.g., daily and monthly sums for weather and climate extremes, respectively). After a brief overview of the commonly used methods (Sect. 2), we present two weather events (Sect. 3) and demonstrate a novel method of eventadjusted extremity evaluation (Sect. 4), which is generally 


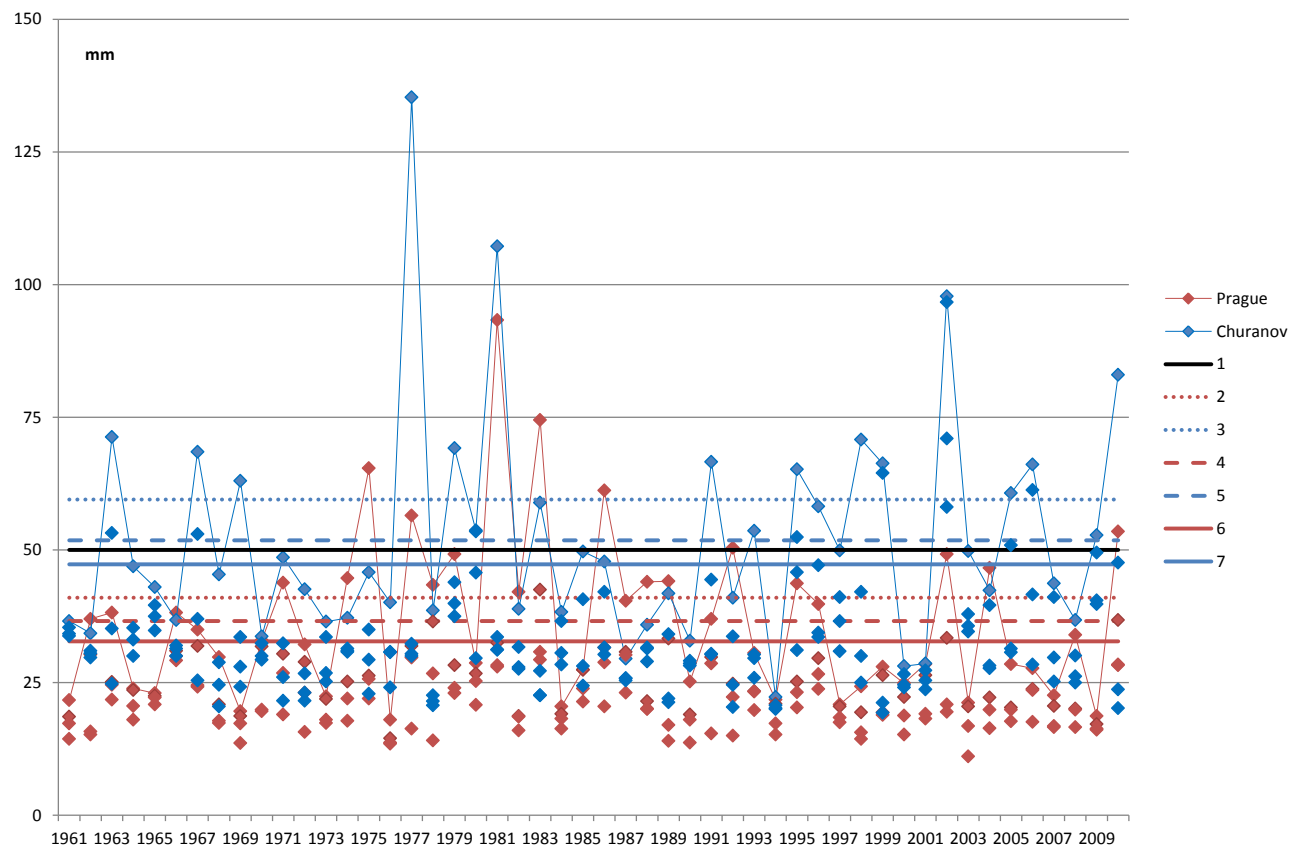

Fig. 1. Four highest daily precipitation totals per year during 1961-2010 in Prague-Ruzyne (364 m a.s.l.) and in Churanov (a peak in Šumava mountains with a height of $1118 \mathrm{~m}$ ). Annual maxima are interconnected by thin lines. The thresholds discussed in the text are depicted by horizontal lines: precipitation total of $50 \mathrm{~mm}$ (1), quantiles $99.9 \%$ in Prague-Ruzyne (2) and in Churanov (3), average annual maxima in Prague-Ruzyne (4) and in Churanov (5), and precipitation totals corresponding to the return period of 2 yr in Prague-Ruzyne (6) and in Churanov (7).

applicable regardless of the type of event. We lastly compare this method with other methods and discuss the benefits and limits of the proposed method (Sect. 5).

\section{Approaches to weather extremity evaluation}

There is no unified method of defining extreme weather events and quantifying their extremeness because "extreme events are generally easy to recognize but difficult to define" (Stephenson, 2008, p. 12). The main reason is that the events can vary in terms of short-term intensity, duration, areal extent, socioeconomic impacts, etc. Beniston et al. (2007) summarized three characteristics that are generally used to identify weather (climate) events as extreme: (i) rarity, (ii) intensity, and (iii) severity (amount of socioeconomic losses or number of casualties). Subsequently, the definition criteria of extreme events also vary as they reflect these aspects.

The concept of severity is useful in many applications: for example, in insurance (Mills, 2005). If we carefully consider aspects of inflation, population and property growth, their redistribution, etc., we can study possible trends (e.g., Balling and Cerveny, 2003; Bouwer, 2011). The aspect of severity can also be very useful in branches in which we need to take into account extremeness in both the driver and the response, such as in ecology (Smith, 2011). Nevertheless, severity always includes not only hazard but also other factors of the risk - exposure and vulnerability - which are not related to natural processes (Stephenson, 2008). Therefore, this measure cannot reasonably be used for evaluation of the extremeness of weather events if we, for example, compare it with the extremity of causal circulation conditions (Cavazos, 1999). For such research, aspects of rarity or intensity (often correlated) seem to be more suitable. Both can be evaluated using data either from individual sites (Sect. 2.1) or from the entire affected area (Sect. 2.2).

\subsection{Point evaluation of extremeness of weather events}

The most popular approach to the extremeness evaluation of weather events is based on quantifying the intensity of a variable at individual sites and on comparing the values with a fixed threshold. For example, precipitation can be considered to be "extreme" if the total reaches $50 \mathrm{~mm}$ or more at a site during $24 \mathrm{~h}$ (probability of exceeding this threshold belongs to ensemble prediction system products prescribed by the WMO, 1992). Extreme events are then defined as peaks over the threshold and, if needed, ordered with respect to the magnitude of the variable. This works if we study a single time series. In contrast, if extreme events are collected from various sites, this approach does not reflect the differences in climate among the sites. In the above-mentioned example, the daily total of $50 \mathrm{~mm}$ can be rather frequent at a site, whereas it is very rare at another one (in Fig. 1, there are 
29 days with daily totals $\mathrm{Rd} \geq 50 \mathrm{~mm}$ in the mountain site Churanov, but only 7 days in Prague). Subsequently, the set of such defined extreme events would be mainly composed of those from exposed sites ( $\sim$ mountain gauges); this fact can substantially influence our inferences from the analysis of the data set.

Considering the rarity of measured values, the set of block maxima obviously also cannot be identified with the complete set of extreme events because extreme events are not equally distributed in time (in Fig. 1, for example, even the fourth highest daily total in 2002 was higher than the annual maximum in the next year in Churanov). Therefore, thresholds are used when studying the rarity of weather as well; nevertheless, thresholds are based on the empirical distribution of the variable at the given site (Stephenson, 2008). They can be defined most easily as quantiles (e.g., Zhang et al., 2011). The set of extreme events then comprises an equal number of events from all sites (in Fig. 1, there are 18 events at both sites if the threshold is set to $99.9 \%$ ). However, the values of the quantiles reflect only the ranking of the totals within the data set rather than real differences among the values (in Fig. 1, for example, the difference between the second and the third highest total is much larger than between the third and the fourth one in Churanov; however, the difference between respective quantiles is constant). We therefore need to search for a more sophisticated method of standardization for station data (Beirlant et al., 2004).

One possible method is to divide actual values by the annual mean or better by the average annual maximum of the representative variable. Using this procedure, we obtain dimensionless (standardized) values that enable us to combine extremes from various sites (in Fig. 1, there are 28 and 25 days with totals higher than the average annual maximum daily total in Churanov and in Prague, respectively). Though standardized values from gauges with different means can be rather similar, the method distinctively favors gauges with a higher variability in the studied variable. Moreover, events with different durations cannot be compared this way because the variability depends, among other things, on the considered length of the events.

A more accurate frequency analysis of extreme events results in return period estimates (see Sect. 4.1 for more details). They reflect the statistical distribution of extreme values and, moreover, they are generally applicable and comparable regardless of, for example, the accumulation period of precipitation (Ramos et al., 2005) and even of the type of studied weather extremes. Hydrologists construct intensityduration-frequency (IDF) curves that make it possible to estimate return periods of observed rainfall intensities over a range of durations (Chow et al., 1988). This implies that this method already reflects the aspect of duration that is further discussed along with the spatial aspect in Sect. 2.2.

It must be noted that the concept of return periods can only be applied under the assumption of stationarity of the climate (Katz, 2010). In a nonstationary climate, return periods do not represent the actual probability of occurrence of a value. Nevertheless, they still can be utilized to compare various events from the viewpoint of weather extremity (see Sect. 4).

\subsection{Regional evaluation of the extremeness of weather events}

In fact, a weather event always affects at least a small area. Obviously, the extremeness of an event increases with the affected area. Though carefully evaluated, data from the only meteorological gauge (in contrast to the hydrological one) do not distinguish large events from only local episodes. Moreover, events also differ in their duration. As a result, more sophisticated methods of evaluating weather extremes need to reflect not only the magnitude of a variable at a site but also both the spatial and temporal aspects - most importantly, the extent and duration of the event, respectively. This challenge corresponds to one of the methodological issues addressed at the WCRP workshop in Paris, September 2010: the requirement of an "enhanced emphasis ... on spatiotemporal scales of extreme events" (Zolina et al., 2011, p. 17).

The temporal aspect of weather extremes is considered more frequently. For instance, not only maximum daily precipitation totals but also 5-day totals belong to standard indices of weather extremes (Frich et al., 2002). However, the duration of the events can be very variable. Biondi et al. (2005) therefore quantified past climatic episodes in terms of two random variables, i.e., duration and magnitude, and calculated conditional probabilities of exceeding both of them. Nevertheless, the extremity of weather is also influenced by the fluctuation of the variable during the event. Begueria et al. (2009) partly took account of this fact; they used declustering of daily precipitation totals for distinguishing individual precipitation events and characterized them by not only magnitude and duration but also by peak intensity.

The spatial aspect of weather extremity can be considered by using the areal average of a variable (rather than individual point measurements). Nevertheless, this method does not reflect variability within the affected area. Moreover, when calculated within a fixed region (an administrative unit, a catchment, etc.), the areal average disadvantages events that are violent but affect only a part of the region. The extremeness of an event depends thus on the extent of the considered region (Konrad, 2001).

Ren et al. (2012) recently tried to combine both aspects together and identified regional extreme events as a string of daily impacted areas. They applied distinct thresholds to daily data to tailor the considered areas and time period to the real extent and duration of the event. This method seems to be promising; however, it is very threshold-sensitive. At this point, we need to address a crucial issue in the evaluation of weather extremity: the limits of both the affected area and the time period are "fuzzy" (not rigorous). Obviously, most weather extremes gradually intensify at the beginning (and they weaken later), and their central parts are surrounded by 
less seriously affected areas. Should only the center of the event (both from the spatial and temporal perspective) with a high magnitude of the variable be taken into account, or should less extreme peripheries also be considered?

This problem can be partly solved by visualization tools, as follows. Andreadis et al. (2005) and, more recently, Sheffield et al. (2009) studied extreme droughts in the US and from a global perspective, respectively. For each extent of the considered area, they determined the highest recorded average drought index. To demonstrate the relationship between the mean severity of drought and the size of the considered area, the authors adopted depth-area-duration (DAD) curves (Nicks and Igo, 1980) for which they replaced rainfall depth by normalized severity of drought. Several severityarea-duration (SAD) curves were combined, one for each considered time window.

Another example of the graphical approach to weather extremity evaluation is the visualization of heavy rainfalls by severity graphs and diagrams suggested by Ramos et al. (2005). (The term "severity" is used by them with a different meaning than by Beniston et al., 2007.) These visualization tools are based on two concepts: IDF curves (see Sect. 2.1) and areal reduction factors (ARFs), which were recently reviewed by Svensson and Jones (2010). Ramos et al. (2005) assumed ARFs to be independent of the return period and applicable over the entire (rather small) area of their interest. For each rain gauge, severity graphs depict return periods of maximum rainfall intensities for gradually increasing rainfall duration. They make it possible to compare different events because they show the variety of return periods among rain gauges and among rainfall durations. Severity diagrams are even more complex; they also include the spatial aspect of extreme events and indicate the possible simultaneous occurrence of extreme point rainfall in time.

SAD curves and mainly severity diagrams are great tools for conducting a complex analysis of weather and climate events. However, because of their graphical character, they cannot readily be used for a "synthesis" - an unambiguous evaluation and comparison of the extremeness of events. At this point, we suggest a method of "event-adjusted" evaluation that is based on optimization of both the considered area and the time duration for every event (Sect. 4).

\section{Reference events and data}

The proposed method of weather extremity evaluation is demonstrated by two precipitation events that affected central Europe in 2010. We used daily precipitation totals from the whole territory of the Czech Republic (measured by the Czech Hydrometeorological Institute). Apart from daily totals, 2-day and 3-day totals were also calculated by the classical moving-window procedure. We also show selected daily totals from neighboring countries in Fig. 2: from Slovakia (Slovak Hydrometeorological Institute), Poland (Institute of

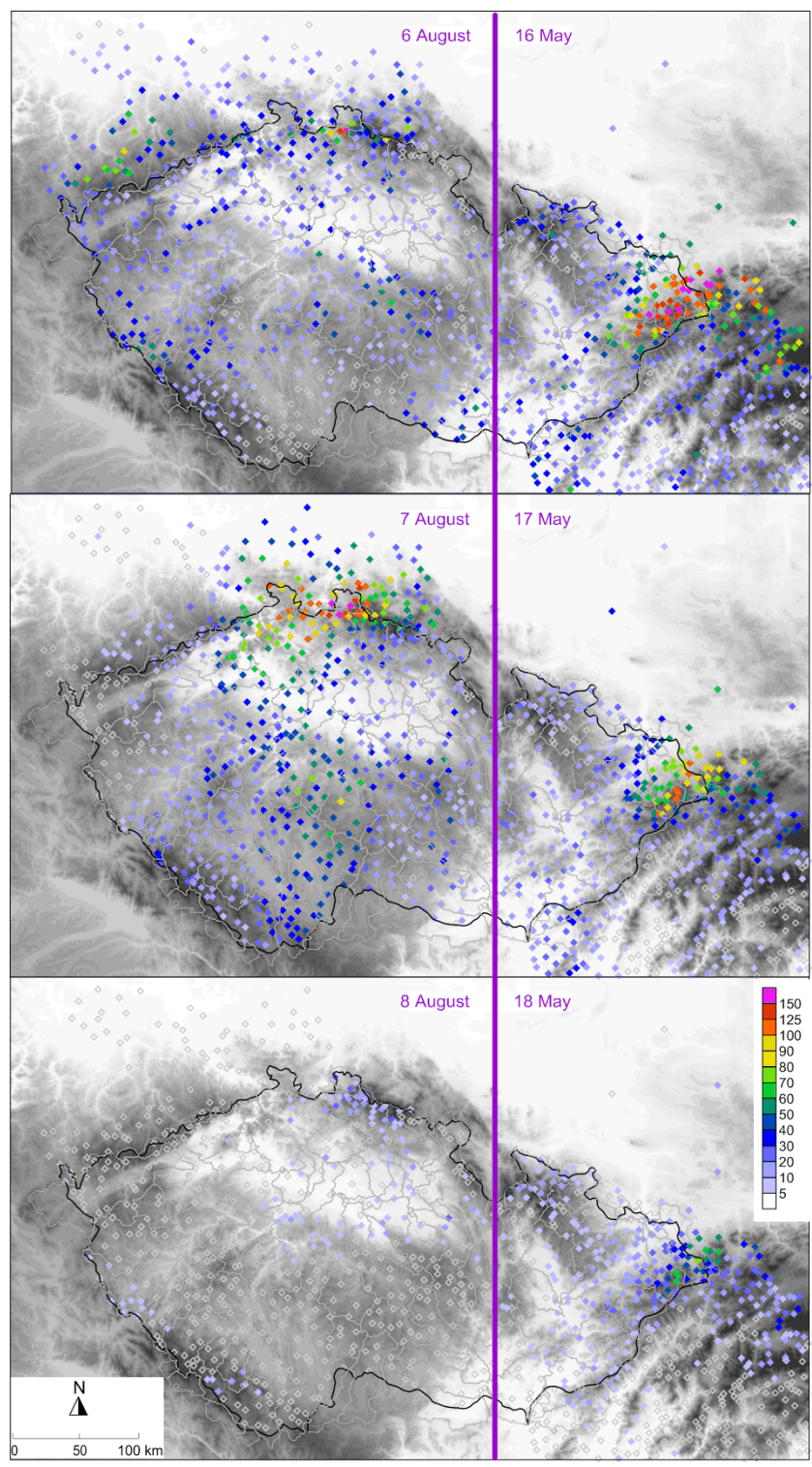

Fig. 2. Daily precipitation totals in May 2010 and in August 2010 (the right and the left part of the figure, respectively). The state border of the Czech Republic is depicted by the black line.

Meteorology and Water Management), and Germany (German Weather Service). Unfortunately, the external data could not be analyzed in terms of their extremeness because we do not know the parameters of the statistical distribution of the precipitation totals for the foreign gauges. Therefore, the analysis of the extremeness of the events is limited by the state border of the Czech Republic.

\subsection{May 2010 event}

Flooding occurred in the eastern part of central Europe in the second half of May 2010. The antecedent saturation of the region was high due to rains that occurred at the beginning 
of the month (Daňhelka and Šercl, 2011). Extra-heavy rains that reached their maximum on 16 May were associated with a cyclone passing from the Mediterranean northeastward, which became nearly stationary over Ukraine for several days. The highest precipitation totals were recorded in the western sector of the cyclone at the state border between the Czech Republic, Slovakia, and Poland. Subsequently, the water stages were even higher than those during the catastrophic flood in July 1997 in some regions, mainly in the upper reaches of the Vistula River in Poland (Bissolli et al., 2011). In the Czech Republic, peak flows reached return periods of more than $50 \mathrm{yr}$ at some gauges. Moreover, because heavy precipitation fell over the flysch Outer Western Carpathians, which are susceptible to landslides, the storm also had geomorphologic impacts. More than 150 mostly small landslides originated only in the eastern part of the Czech Republic, including a kilometer-long rockslide along the southern slope of Mt. Girová in the Beskydy mountains (Panek et al., 2011).

\subsection{August 2010 event}

During the first days of August 2010, flooding occurred in many rivers over the western part of the Czech Republic, with high return periods concentrated in a rather small region at the state border between the Czech Republic, Germany, and Poland (Fig. 2). Heavy rains reaching their maximum on 7 August were more concentrated in time than they were in May. They were associated with a rather shallow cyclone passing from the Mediterranean to the north. The most affected river basins were the Lausitzer Neisse (a left-sided tributary of the Oder) and the neighboring right-sided tributaries of the Elbe (Müller and Walther, 2011). The water levels were the highest ever recorded at some smaller streams. Moreover, the flood caused the Niedów Dam on the river Witka to break.

\section{Event-adjusted evaluation of weather extremity}

The proposed method of weather extremity evaluation consists of three steps presented in the following sections. We first evaluate the rarity of a representative meteorological variable at individual sites (Sect. 4.1). Despite the procedure used by Ramos et al. (2005) and other authors, we do not transform the detected point return periods into the areal ones (Sect. 2.2). Instead of this process, we interpolate the point return period data in space so that we can estimate a point return period in every pixel of the studied area (Sect. 4.2). We lastly accumulate return periods from individual pixels and look for the optimal area and time period in which the proposed measure of extremity was the highest (Sect. 4.3).

\subsection{Point evaluation of weather extremity}

As we have already discussed in Sect. 2.1, return periods are likely the most accurate instrument for quantifying the rarity of measured data at individual sites because they reflect the shape of the statistical distribution of data. The first step of the proposed methodology is a standard estimation of return periods of a representative variable at individual sites. Nevertheless, the estimation is performed separately for various time windows. In our case studies, return periods of daily, 2-day, and 3-day precipitation totals were assessed using the generalized extreme value (GEV) distribution (Hosking and Wallis, 1997) because it was found to represent a suitable model for precipitation extremes in most regions of the Czech Republic (Kyselý and Picek, 2007). The GEV distribution was applied as the parametric model for annual maxima of precipitation totals. Parameters of the GEV distribution were estimated by means of the L-moment algorithm (Hosking and Wallis, 1997) and the regional frequency analysis - region-of-influence (ROI) method (Burn, 1990). The ROI method employs "homogenous regions", in which all regional data, weighted by a dissimilarity measure, are used for estimating parameters of the distribution of extremes at the site of interest. The advantage of the ROI method compared with the local analysis is that sampling variations in the estimates of model parameters and high quantiles may be substantially reduced, and the inference becomes more robust. Most recently, this fact was confirmed also for the August 2010 reference event (Kyselý et al., 2013).

The application of the ROI method allowed us to utilize data from more than 600 rain gauges from the Czech Republic with daily data series of at least $20 \mathrm{yr}$ and to consider the estimates of return periods up to $1000 \mathrm{yr}$. In fact, so high a value did not occur either in May or in August 2010. However, the maximum return period reached at an individual gauge does not reflect the spatial aspect of weather extremity, as demonstrated in the following sections.

\subsection{Spatial interpolation of return period data}

Ramos et al. (2005) stated that attributing a single return period to a storm event observed over a given area is not straightforward because the severity of a storm varies depending on the considered space- and time integration scales. Nevertheless, we decided to solve the problem in a different way than they did - namely by the interpolation of point return periods into a regular grid. Our motivation is to avoid the uncertainty regarding ARF (see Sect. 2.2).

A common procedure involves the interpolation of statistical distribution parameters from individual gauges (Ceresetti et al., 2012). However, we were confronted with a different task: interpolation of return period values. When searching for a proper interpolation method, we excluded all standard methods because of the exponential nature of the GEV distribution that the return period values are derived from (see 
discussion in Sect. 5). We therefore first transformed return periods into their common logarithms. We then interpolated the logarithms by linear kriging into a regular grid with a horizontal resolution of $1 \mathrm{~km}$. Lastly, the interpolated data were reconverted into return period values using the inverse logarithmic transformation. The procedure is repeated for all considered time windows.

The results for our reference events are depicted in Fig. 3. Despite the similarities in maximum daily totals (Fig. 2), the respective return periods were substantially higher in August than in May. The events were mostly similar regarding return periods of 3-day totals because of the shorter duration of the August precipitation event. While precipitation fell in the mountain region that is prone to heavy, long-lasting rains in May (Kyselý and Picek, 2007), the August event also affected regions where heavy rains are rare.

\subsection{Optimization of the considered area and the time window}

We stated in Sect. 4.1 that the maximum return period reached at an individual gauge does not reflect the spatial aspect of weather extremity. However, neither does the average within the whole Czech Republic because heavy rains usually affect only a part of the territory, as was the case both in May and in August 2010 (Fig. 2). Moreover, the events hit different regions with different extents, so their extremeness cannot readily be evaluated within a unified area. We therefore study a unique area for each weather event.

Obviously, the considered area has to comprise the region where the studied phenomenon reached the highest extremeness. The area does not have to be compact because of, for example, the role of topography (see Fig. 2). Thus, we sort grid pixels with respect to return period values in descending order (Fig. 4) and average the pixels with the highest values. Because of the above-mentioned exponential nature of the GEV distribution, we calculate the spatial geometric (instead of arithmetic) mean of return periods [yr]

$G_{t a}=\sqrt[n]{\prod_{i=1}^{n} N_{t i}}$

where $N_{t i}$ is the return period of the studied variable in a grid point $i$ and a time period $t$ and $n$ is the number of considered grid points each representing $1 \mathrm{~km}^{2}$. The problem is that the mean return period continuously decreases with the extending area (Fig. 5). How does one recognize the edge that delimits the optimal area? Moreover, how does one select the optimal duration of the event when the curves intersect each other (meaning the optimal duration changes with the size of the considered area)? The classical approach is to fix subjectively the time window (e.g., 3 days) and either the considered return periods (e.g., by the threshold $N=10 \mathrm{yr}$ ) or the extent of the considered area (e.g., $n=1000$ ). We search for an alternative way by adjusting the thresholds to the actual event.

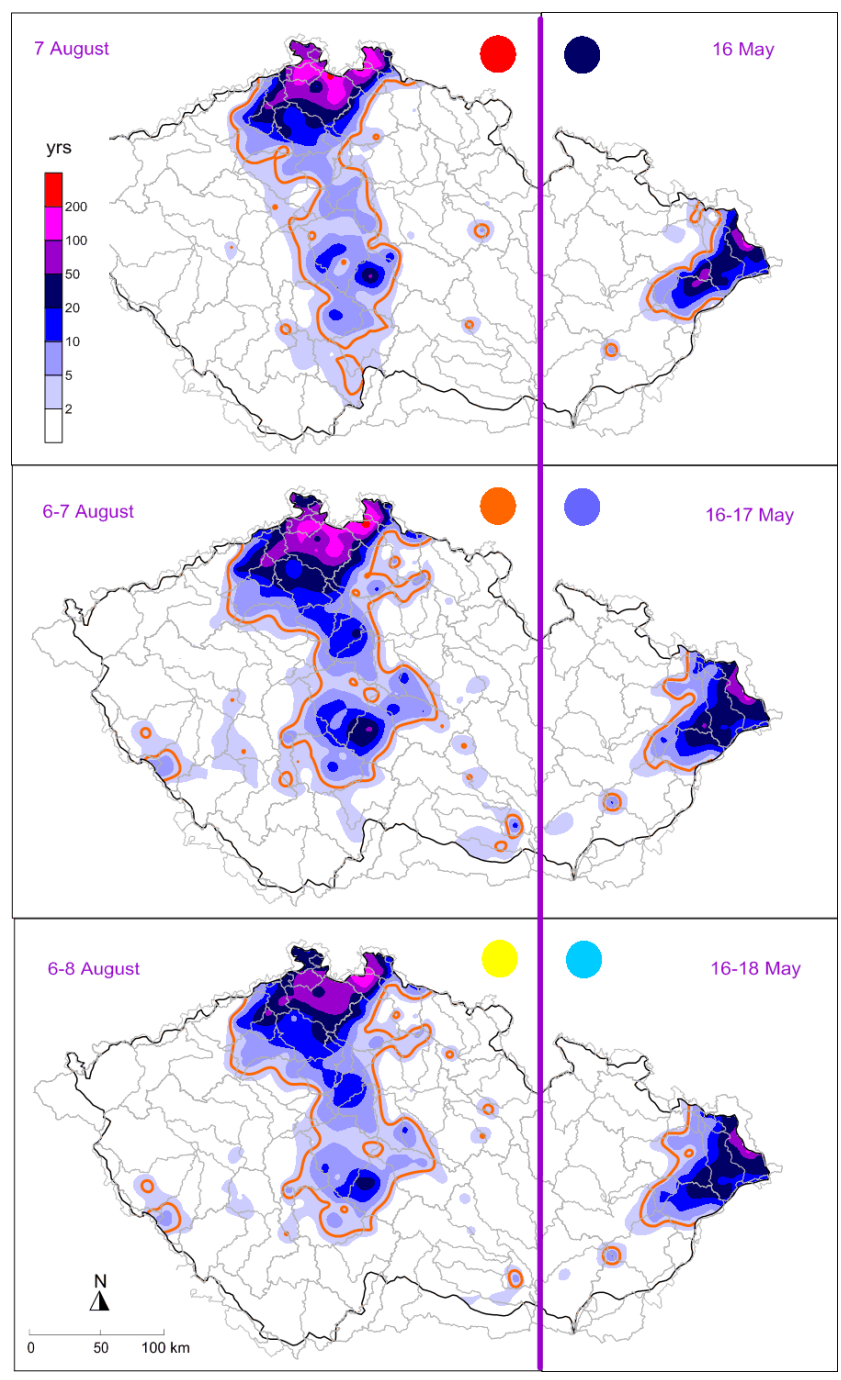

Fig. 3. Return periods of precipitation totals in May 2010 and in August 2010 (the right and left part of the figure, respectively), interpolated into the $1 \mathrm{~km}$ grid. Each event is represented by a 1-day, 2-day, and 3-day period with maximum return periods. The optimized areas affected in the given time period (see Sect. 4.3) are depicted by orange lines. Colors of circles correspond with Figs. 4 , 5,6 , and 7 .

Our proposal is based on the assumption that the most extreme event has to be both intense (rare) and large. Lower extremeness of other events can be due to the decrease in the intensity (rarity) and/or the spatial extent of an event. As a result, a proper extremity index should, in our opinion, be a product of a measure of rarity and of a measure of the spatial extent. Regarding the first factor, we use $\log \left(G_{t a}\right)$ instead of pure $G_{t a}$ because of the exponential nature of return periods. If the second factor of the product was simply the area $(a)$, the product would increase continuously because $\log \left(G_{t a}\right)$ decreases at a much lower rate than $a$ increases. Obviously, the spatial extent should be considered with a smaller weight 


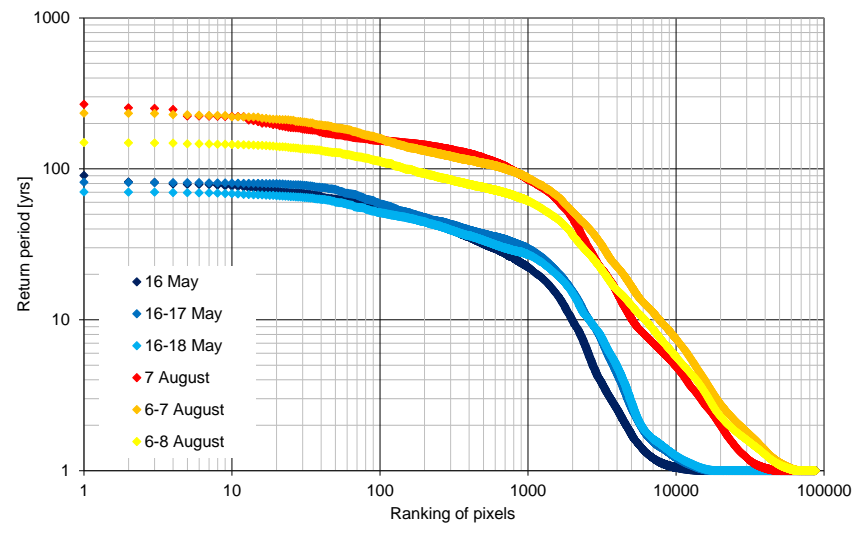

Fig. 4. The distribution of return periods of precipitation totals in individual grid pixels during reference events.

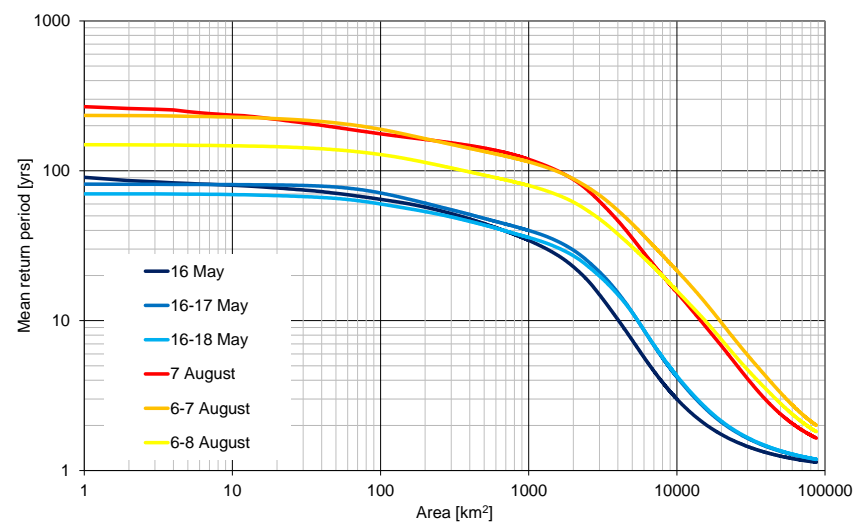

Fig. 5. Changes in geometric means of ordered return periods of precipitation totals in Fig. 4 as a function of increasing area.

in order to balance it with the measure of the rarity $\log \left(G_{t a}\right)$ which has a linear nature. We have chosen a simple and reasonable way to reduce the weight of $a$ : the square root that represents the length. The main reason for this is that this approach enables the affected area to be unambiguously delimited, as presented below.

We proposed the following variable $E_{t a}[\log (\mathrm{yr}) \mathrm{km}]$ :

$E_{t a}=\log \left(G_{t a}\right) R=\frac{\sum_{i=1}^{n} \log \left(N_{t i}\right)}{n} \frac{\sqrt{a}}{\sqrt{\pi}}$,

which is defined by a product of $\log \left(G_{t a}\right)$ and of the radius $R$ of a circle of the same area $(a)$ as the one over which $G_{t a}$ is taken. Alternatively, $\log \left(G_{t a}\right)$ can be simply computed also as the arithmetic mean of common logarithms of return periods. Unlike $G_{t a}$ (Fig. 5), $E_{t a}$ increases initially as we accumulate the pixels with high return periods. However, once the return periods are not high enough in the additional accumulated pixels, the value of $E_{t a}$ starts to decrease. This occurs when the decrease in the return periods is more significant than the increase in the accumulated area (Fig. 6). The tipping point of the curve is the focus of our interest because

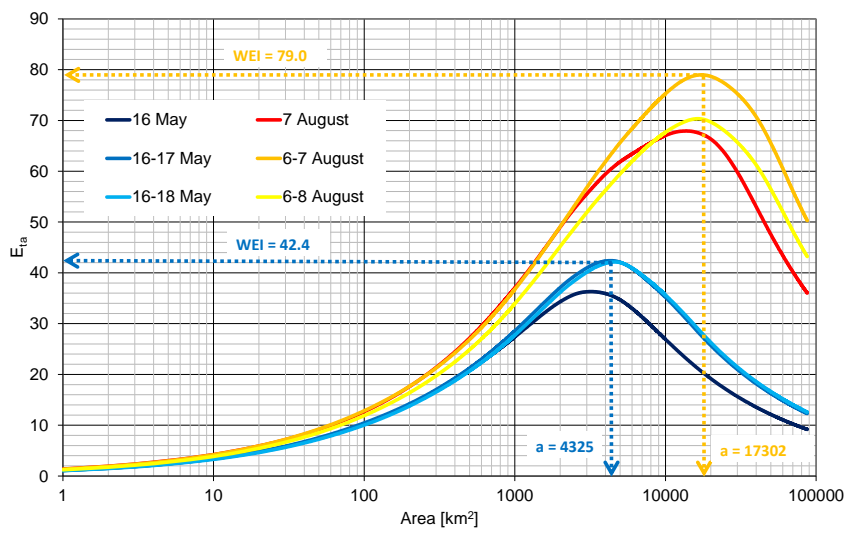

Fig. 6. Changes in $E_{t a}$ values with the increasing extent of the considered area. The values of the WEI and the respective areas are depicted by arrows.

the maximum of $E_{t a}$ characterizes the extremeness of the phenomenon within the time period $t$. This point represents the inflection point of the curve in Fig. 5; at this point, the decrease in the mean extremeness represented by $\log \left(G_{t a}\right)$ becomes more significant than the increase in the area represented by $R$.

We lastly choose the time period for which $E_{t a}$ reached its maximum during the event. We call this value the weather extremity index (WEI) because it represents the searched extremeness of the event. Its unit is $\log (\mathrm{yr}) \mathrm{km}$. Now, we can also define the affected area $a$, the duration $t$, and the respective geometric mean of return periods $G_{t a}$ complying with the relation $E_{t a}=$ WEI.

Any weather or climate event can be evaluated by the WEI and by related characteristics. The comparison of the two studied precipitation events is demonstrated by diagrams in Fig. 7. The main difference is that the affected area $a$ was much larger (within the Czech Republic) in August. However, $\log \left(G_{t a}\right)$ was slightly lower because compared with May, a larger part of the affected area was characterized by rains with relatively low return periods in August (see also Fig. 3). Both events were rated as 2-day events; nevertheless, the difference between 2-day and 3-day values of $E_{t a}$ was negligible in May.

\section{Discussion}

In the couple of presented examples, we used daily precipitation totals when evaluating the extremeness of heavy rain events. To evaluate longer events properly, we estimated return periods of totals accumulated during 2 and 3 days (even longer time windows can be studied). In contrast, a precipitation event can last less than 1 day. Obviously, it would be better to use short-term precipitation intensities and their return periods ( $3 \mathrm{~h}, 6 \mathrm{~h}$, etc.). However, the density and length of their data series are not sufficient for these purposes. As a 

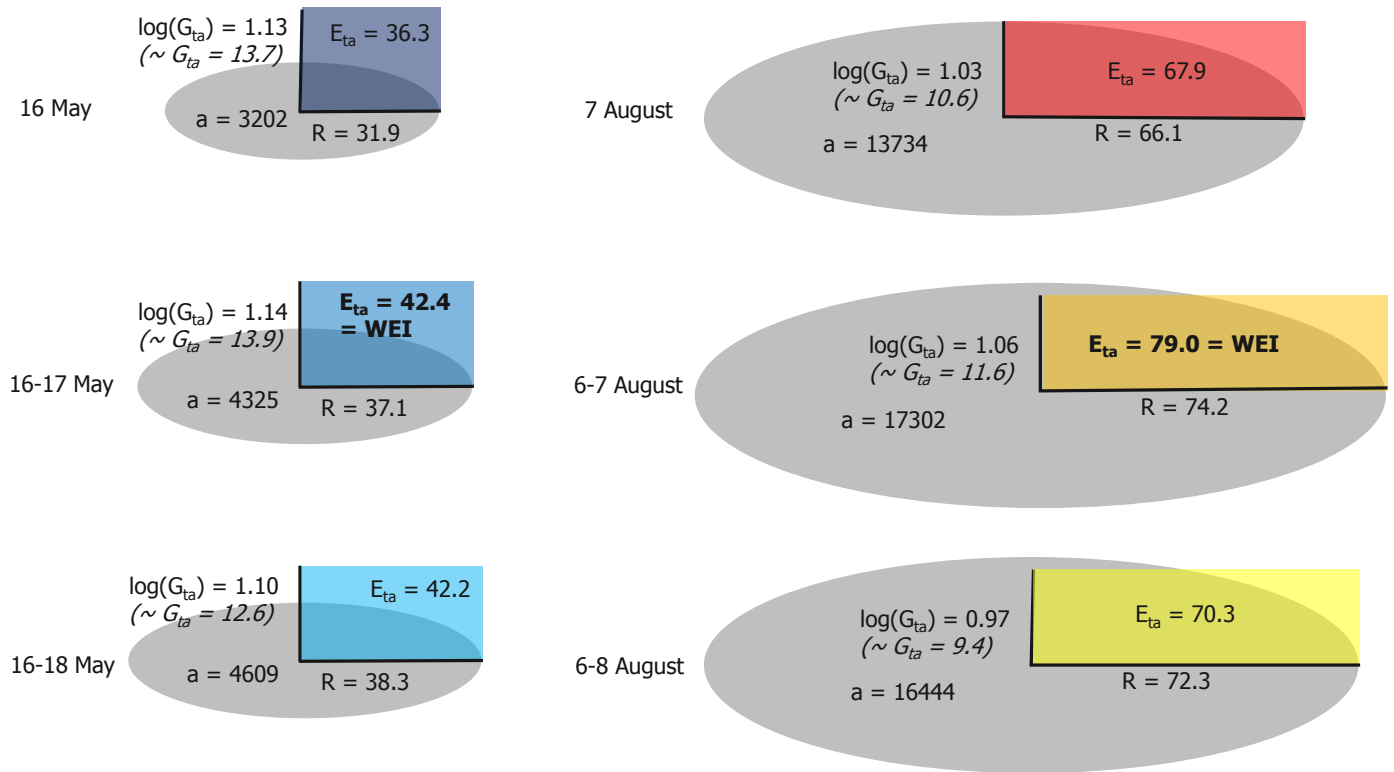

Fig. 7. Demonstration of $E_{t a}$ and WEI values as products of $\log \left(G_{t a}\right)$ (the common logarithm of the geometric mean of return periods) and $R$ (radius of the circle area equivalent to the considered area $a$ ). Units are as follows: $R[\mathrm{~km}], a\left[\mathrm{~km}^{2}\right], G_{t a}[\mathrm{yr}], E_{t a}$ and WEI $[\log (\mathrm{yr}) \mathrm{km}]$.

result, it should be taken into account that the extremeness of such events (usually produced by convective storms) can be slightly underestimated by the WEI because they are compared by the same tool with events when precipitation actually fell the whole day. For example, return periods of $6 \mathrm{~h}$ totals would be higher than if they are evaluated as 1-day totals. In future we plan to also employ return periods of short-term precipitation intensities using temporal statistical downscaling of daily totals.

The estimation of return periods at gauges is methodsensitive, which can increase the uncertainty of the extremity evaluation. We applied the GEV distribution; parameters were estimated by means of the L-moment algorithm. The distribution of precipitation extremes is usually heavy-tailed. If not, return period estimates can reach unrealistically high values. We therefore decided to restrict the estimates to a maximum of $1000 \mathrm{yr}$. We also used the ROI method, making the results more robust. Even if a less sophisticated method is used, the influence of this type of uncertainty is substantially reduced in our methodology because we use common logarithms of return periods rather than mere values of them.

An additional step in the suggested methodology is the interpolation of point values of return periods into a regular grid. We do not estimate return periods of areal precipitation totals. On the other hand, this approach prevents us from increasing the uncertainty by interpolation both precipitation totals and GEV parameters. Again, the interpolation method can influence the acquired results. Because the spatial distribution of return period values does not fully correspond with the respective totals, methods used for precipitation interpolation cannot reasonably be applied in this case. A strong

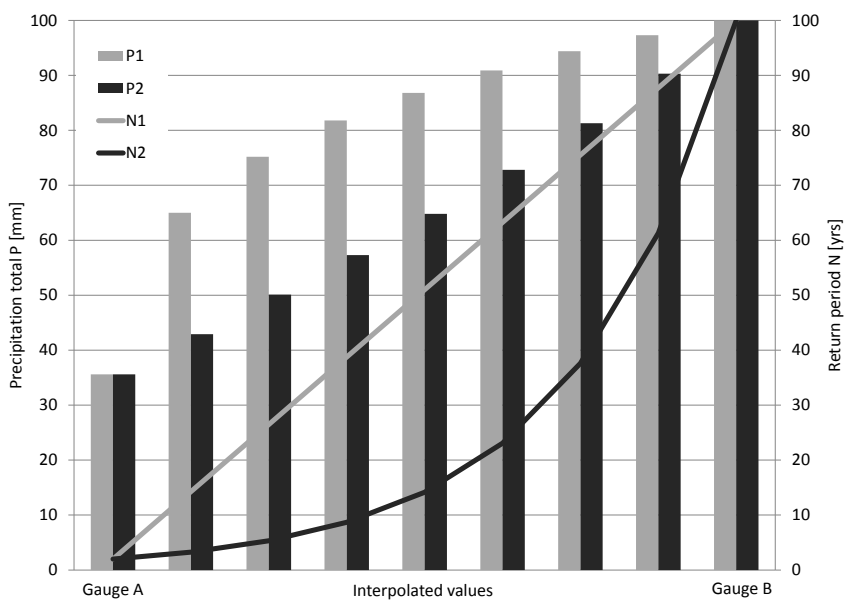

Fig. 8. Precipitation totals $(P)$ between two gauges, calculated from differently interpolated return period values $(N)$ : (1) linear interpolation of return periods, and (2) linear interpolation of common logarithms of return periods.

emphasis should be placed on the finding that if return periods are interpolated, it is necessary to reflect their nonlinear dependence on the totals. We decided to interpolate common logarithms; our reasoning can be demonstrated by the following example (Fig. 8).

Consider two gauges at the distance of $8 \mathrm{~km}$, having the same parameters of the GEV distribution. Gauge A measured a daily total of $35.6 \mathrm{~mm}$, which corresponds to the return period of $2 \mathrm{yr}$; gauge B measured $100 \mathrm{~mm}$ (return period of $100 \mathrm{yr}$ ). The application of linear interpolation of the 
Table 1. Comparison of reference events by characteristics discussed in Sect. 2 and by the WEI: maximum daily precipitation total at a site $\left(\operatorname{Max} R_{\mathrm{d}}\right)$, maximum ratio of $\operatorname{Max} R_{\mathrm{d}}$ to the average annual maximum daily total at a site (Max $\left.R_{\mathrm{d}} / \operatorname{Avg}\left[\max \mathrm{a} R_{\mathrm{d}}\right]\right)$, maximum return period of a daily precipitation total at a site $(\operatorname{Max} N)$, maximum mean daily precipitation total within the Czech Republic (Mean $\left.R_{\mathrm{d}}\right)$, and weather extremity index (WEI). The values only represent the territory of the Czech Republic.

\begin{tabular}{lrlllll}
\hline & \multicolumn{2}{c}{ May } & & \multicolumn{2}{c}{ August } \\
\cline { 2 - 3 } \cline { 5 - 6 } Characteristic [unit] & Value & Station/region & & Value & Station/region \\
\hline MaxRd [mm] & 179.8 & Třinec & & 179.0 & Hejnice \\
MaxRd/Avg $\left(\max _{\mathrm{a}} R_{\mathrm{d}}\right)$ & 3.04 & Třinec & & 3.37 & Mařenice \\
Max $N[\mathrm{yr}]$ & 160 & Třinec & & 284 & Mařenice \\
MeanRd [mm] & 7.6 & Czechia & & 21.7 & Czechia \\
WEI $[\log (\mathrm{yr}) \mathrm{km}]$ & 42.39 & $4325 \mathrm{~km}^{2}$ & & 78.98 & $17302 \mathrm{~km}^{2}$ \\
\hline
\end{tabular}

return period values leads to an increase in the return period by the value of $12.25 \mathrm{yr}$ per $1 \mathrm{~km}$ in the line from gauge A to gauge $\mathrm{B}$. As a result, corresponding precipitation totals increase much more rapidly in the vicinity of gauge A than B. In fact, we could expect a linear increase in precipitation between A and B, which is satisfied when logarithms of return period values are interpolated.

The final step of our methodology optimizes the considered area and the time window for every studied event. Even if the area is divided into several parts, or if days with heavy rains are separated by a slightly drier episode, they are considered as a whole due to the accumulated effect of precipitation. We aggregate grid pixels with high return period values and compute their geometric mean within the given area. The optimization is enabled by multiplication of the common logarithm of the geometric mean by the radius of an equivalent circle area. We find the product $E_{t a}$ of these two factors well balanced because both are linear in nature. As a result, $E_{t a}$ increases with increasing $a$ only as long as pixels with high return periods are added. This shape of the $E_{t a}$ curve allows for objective optimization of the considered area and comparison of a weather (climate) extreme with other events.

In Table 1, the values of the WEI are compared with other characteristics of extremity that were discussed in Sect. 2. Aside from the maximum daily total at a site, the August event was more extreme in the Czech Republic with respect to all other characteristics, including the WEI; this corresponds to the hydrological response, which was also more extreme in August, when return periods of peak flows surpassed $100 \mathrm{yr}$ at some rivers in northern Bohemia (Kaspar et al., 2013).

Nevertheless, the WEI can be applied regardless the type of weather (climate) extremes. It reflects both the spatial and the temporal aspects of the studied event. Unlike classical indices, the WEI is not threshold-dependent in terms of the considered area and the applied time window. As a result, it enables the extremeness of rather heterogenous events to be compared.

\section{Conclusions}

The suggested methodology takes into account both the spatial and the temporal aspects of weather and climate extremes and is generally applicable regardless of the studied phenomenon (heavy rains, heat waves, cold spells, windstorms, etc.). The only condition is that the phenomenon is quantified by a proper variable (precipitation totals, daily temperature maxima and minima, etc.). The methodology reflects spatial differences in the climatology of the variable; return periods are therefore utilized rather than mere values of the variable. The evaluation of extremeness is "event-adjusted", which means that it is based on optimization of both the considered area and time duration for every event. The suggested WEI makes it possible to evaluate weather and climate extremes quantitatively. As a result, extremes can be studied more precisely from the viewpoint of possible recent and future changes in their frequency, seasonal distribution, circulation conditions accompanying them, etc.

The WEI can be computed within any region of interest (for example, administrative units). We demonstrated the methodology within the territory of the Czech Republic and prepare several papers regarding temperature, precipitation, and wind extremes in the Czech territory. Nevertheless, both presented precipitation events also affected neighboring countries. The events could also be evaluated as a whole if respective data were at our disposal. Furthermore, if the WEI of a precipitation event is computed within individual catchments, values of the WEI can be easily compared with runoff extremeness, thus making it possible to study relationships between extremeness of precipitation events and of subsequent floods.

There is one more aspect of weather and climate extremes that has not been discussed in the presented paper: we can consider not only the spatial differences in climatology of the studied phenomenon but also the temporal ones. For example, heavy rains are concentrated in summer in the Czech Republic (Tolasz et al., 2007). If we define extremes as the events that are the most different from seasonally normal conditions, then they can occur during the whole year. In 
addition, if properly selected, they should be randomly and, to a certain extent, evenly distributed within the annual cycle. We would like to focus on these issues in our next study.

Acknowledgements. The research presented in this study is supported by the Czech Science Foundation under the project GACR P209/11/1990. Precipitation data were provided by the Czech Hydrometeorological Institute for research purposes. We would also like to thank J. Kyselý and L. Gaál from the Institute of Atmospheric Physics in Prague for implementing the ROI method.

Edited by: M.-C. Llasat

Reviewed by: two anonymous referees

\section{References}

Alexander, L. V., Zhang, X., Peterson, T. C., Caesar, J., Gleason, B., Klein Tank, A. M. G., Haylock, M., Collins, D., Trewin, B., Rahimzadeh, F. Tagipour, A., Rupa Kumar, K., Revadekar, J., Griffiths, G., Vincent, L., Stephenson, D. B., Burn, J., Aguilar, E., Brunet, M. Taylor, M., New, M., Zhai, P., Rusticucci, M., and Vazquez-Aguirre, J. L.: Global observed changes in daily climate extremes of temperature and precipitation, J. Geophys. Res., 111, D05109, doi:10.1029/2005JD006290, 2006.

Andreadis, K. M., Clark, E. A., Wood, A. W., Hamlet, A. F., and Lettenmaier, D. P.: Twentieth-century drought in the conterminous United States, J. Hydrometeor., 6, 985-1001, 2005.

Balling, R. C. and Cerveny, R. S.: Compilation and discussion of trends in severe storms in the United States: Popular perception v. climate reality, Nat. Hazards, 29, 103-112, 2003.

Begueria, S., Vicente-Serrano, S. M., Lopez-Moreno, J. I., and Garcia-Ruiz, J. M.: Annual and seasonal mapping of peak intensity, magnitude and duration of extreme precipitation events across a climatic gradient, northeast Spain, Int. J. Climatol., 29, 1759-1779, 2009.

Beirlant, J., Goegebeur, Y., Teugels, J., and Segers, J.: Statistics of Extremes: Theory and Applications, John Wiley \& Sons, Chichester, 2004.

Beniston, M. and Stephenson, D. B.: Extreme climatic events and their evolution under changing climatic conditions, Glob. Planet. Change, 44, 1-9, 2004.

Beniston, M., Stephenson, D. B., Christensen, O. B., Ferro, C. A. T., Frei, C., Goyette, S., Halsnaes, K., Holt, T., Jylha, K., Koffi, B., Palutikof, J., Scholl, R., Semmler, T., and Woth, K.: Future extreme events in European climate: an exploration of regional climate model projections, Climatic Change, 81, 71-95, 2007.

Biondi, F., Kozubowski, T. J., and Panorska, A. K.: A new model for quantifying climate episodes, Int. J. Climatol., 25, 1253-1264, 2005.

Bissolli, P., Friedrich, K., Rapp, J., and Ziese, M.: Flooding in eastern central Europe in May 2010 - reasons, evolution and climatological assessment, Weather, 66, 147-153, 2011.

Bouwer, L. M.: Have disaster losses increased due to anthropogenic climate change? B. Am. Meteorol. Soc., 92, 39-45, 2011.

Burn, D. H.: Evaluation of regional flood frequency analysis with a region of influence approach, Water Resour. Res., 26, 22572265,1990 .
Cavazos, T.: Large-scale circulation anomalies conducive to extreme precipitation events and derivation of daily rainfall in northeastern Mexico and southeastern Texas, J. Climate, 12, 1506-1523, 1999.

Ceresetti, D., Ursu, E., Carreau, J., Anquetin, S., Creutin, J. D., Gardes, L., Girard, S., and Molinié, G.: Evaluation of classical spatial-analysis schemes of extreme rainfall, Nat. Hazards Earth Syst. Sci., 12, 3229-3240, doi:10.5194/nhess-12-32292012, 2012.

Chow, V. T., Maidment, D., and Mays, L. M.: Applied Hydrology, McGraw-Hill Book Co., New York, 1988.

Cutter, S. L., Gall, M., and Emrich, C. T.: Toward a comprehensive loss inventory of weather and climate hazards, in: Climate extremes and society, edited by: Diaz, H. F. and Murnane, R. J., Cambridge University Press, New York, 279-295, doi:10.1017/CBO9780511535840.017, 2008.

Danhelka, J. and Sercl, P.: Floods in the Czech Republic in 2010. Meteorologicke zpravy, 64, 4-9, 2011(in Czech, with an English abstract).

Diaz, H. F. and Murnane, R. J.: The significance of weather and climate extremes to society: an introduction, in: Climate extremes and society, edited by: Diaz, H. F. and Murnane, R. J., Cambridge University Press, New York, 1-7, doi:10.1017/CBO9780511535840.003, 2008.

Frich, P., Alexander, L. V., Della-Marta, P., Gleason, B., Haylock, M., Klein Tank, A. M. G., and Peterson, T.: Observed coherent changes in climatic extremes during the second half of the twentieth century, Clim. Res., 19, 193-212, 2002.

Hegerl, G. C., Zwies, F. W., Stott, P. A., and Kharin, V. V.: Detectability of anthropogenic changes in annual temperature and precipitation extremes, J. Climate, 17, 3683-3700, 2004.

Homar, V., Jansà, A., Campins, J., Genovés, A., and Ramis, C.: Towards a systematic climatology of sensitivities of Mediterranean high impact weather: a contribution based on intense cyclones, Nat. Hazards Earth Syst. Sci., 7, 445-454, doi:10.5194/nhess-7445-2007, 2007.

Hosking, J. R. M. and Wallis, J. R.: Regional frequency analysis: an approach based on L-moments, Cambridge University Press, New York, 1997.

Kaspar, M., Müller, M., and Pecho, J.: Comparison of meteorological conditions during May and August 2010 floods in Central Europe, AUC Geographica, 48, 27-34, 2013.

Katz, R. W.: Statistics of extremes in climate change, Climatic Change, 100, 71-76, 2010.

Klein Tank, A. M. G., Peterson, T. C., Quadir, D. A., Dorji, S., Zou, X., Tang, H., Santhosh, K., Joshi, U. R., Jaswal, A. K., Kolli, R. K., Sikder, A. B., Deshpande, N. R., Revadekar, J. V., Yeleuova, K. Vandasheva, S., Faleyeva, M. Gomboluudev, P., Budhathoki, K. P., Hussain, A., Afzaal, M., Chandrapala, L., Anvar, H., Amanmurad, D., Asanova, V. S., Jones, P. D., New, M G., and Spektorman, T.: Changes in daily temperature and precipitation extremes in central and south Asia, J. Geophys. Res. 111, D16105, doi:10.1029/2005JD006316, 2006.

Konrad, C. E.: The most extreme precipitation events over the Eastern United States from 1950 to 1996: considerations of scale, J. Hydrometeor., 2, 309-325, 2001.

Kyselý, J. and Picek, J.: Regional growth curves and improved design value estimates of extreme precipitation events in the Czech Republic, Clim. Res., 33, 243-255, 2007. 
Kyselý, J., Gaal, L., Picek, J., and Schindler, M.: Return periods of the August 2010 heavy precipitation in northern Bohemia (Czech Republic) in present climate and under climate change, J. Water Clim. Chang., 4, 265-286, doi:10.2166/wcc.2013.051, 2013.

Lupikasza, E.: Relationships between occurrence of high precipitation and atmospheric circulation in Poland using different classifications of circulation types, Phys. Chem. Earth, 35, 448-455, 2010.

Mills, E.: Insurance in a climate of change, Science, 309, 10401044, doi:10.1126/science.1112121, 2005.

Müller, M. and Kaspar, M.: Quantitative aspect in circulation type classifications - an example based on evaluation of moisture flux anomalies, Phys. Chem. Earth, 35, 484-490, 2010.

Müller, U. and Walther, P.: The Neisse Flood 2010 - Analysis and Consequences, Wasserwirtschaft, 101, 10-14, 2011 (in German).

Nicks, A. D. and Igo, F. A.: A depth-area-duration model of storm rainfall in the Southern Great Plains, Water Resour. Res., 16, 939-945, 1980.

Panek, T., Brazdil, R., Klimes, J. Smolkova, V., Hradecky, J., and Zahradnicek, P.: Rainfall-induced landslide event of May 2010 in the eastern part of the Czech Republic, Landslides, 8, 507516, 2011.

Ramos, M. H., Creutin, J. D., and Leblois, E.: Visualization of storm severity, J. Hydrol., 315, 295-307, 2005.

Ren, F. M., Cui, D. L., Gong, Z. Q., Wang, Y. J., Zou, X. K., Li, Y. P., Wang, S. G., and Wang, X. L.: An objective identification technique for regional extreme events, J. Climate, 25, 7015-7027, 2012.

Sheffield, J., Andreadis, K. M., Wood, E. F., and Lettenmaier, D. P.: Global and continental drought in the second half of the twentieth century: Severity-area-duration analysis and temporal variability of large-scale events, J. Climate, 22, 1962-1981, 2009.
Smith, M. D.: An ecological perspective on extreme climatic events: a synthetic definition and framework to guide future research, J. Ecol., 99, 656-663, doi:10.1111/j.1365-2745.2011.01798.x, 2011.

Stephenson, D. B.: Definition, diagnosis, and origin of extreme weather and climate events, in: Climate extremes and society, edited by: Diaz, H. F. and Murnane, R. J., Cambridge University Press, New York, 11-23, doi:10.1017/CBO9780511535840.004, 2008.

Svensson, C. and Jones, D. A.: Review of methods for deriving areal reduction factors, J. Flood Risk Manag., 3, 232-245, 2010.

Tolasz, R., Mikova, T., Valerianova, A., and Vozenilek, V. (Eds.): Climate atlas of Czechia, Czech Hydrometeorological Institute, Prague, Czech Republic, 2007.

Visser, H. and Petersen, A. C.: Inferences on weather extremes and weather-related disasters: a review of statistical methods, Clim. Past, 8, 265-286, doi:10.5194/cp-8-265-2012, 2012.

Wigley, T. M. L.: The effect of changing climate on the frequency of absolute extreme events, Clim. Change, 97, 67-76, 2009. Reprinted from Climate Monitor, 17, 44-55, 1988.

WMO: Manual on the global data-processing system, World Meteorological Organization, Geneva, 1992.

Zhang, X. B., Alexander, L., Hegerl, G. C., Jones, P, Klein Tank, A., Peterson, T. C., Trewin, B, and Zwiers, F. W.: Indices for monitoring changes in extremes based on daily temperature and precipitation data, Wiley Interdiscip. Rev.-Clim. Chang., 2, 851870, 2011.

Zolina, O., Demuth, S., Detemmerman, V., Gulev, S., Gutowski, W., Klein Tank, A., Stephenson, D., Stewart, R. Trenberth, K., and Zwiers, F.: WCRP (GEWEX/CLIVAR) and UNESCO (IHP) metrics and methodologies of estimation of extreme climate events workshop, WCRP Informal/Series Report 9/2011, available at: http://www.wcrp-climate.org/documents/Report_9_ 2011_Paris.pdf (last access: 2 February 2013), 2011. 